\title{
El Estado como capataz. Política ambiental, gobernanza y reterritorialización en el bosque tropical del Caribe mexicano
}

\section{The state as a foreman. Environmental policy, governance and reterritorialization in the tropical forest of the Mexican Caribbean}

\section{Ángeles A. López Santillán*}

\section{Resumen}

El análisis de la gobernanza ambiental se ha orientado a identificar a los actores en la arena política, sin enfatizar en su condición como esquema regulatorio en el marco de la acumulación del capital. Aquí analizo al Estado mexicano como el actor central para ejecutar los pagos por servicios ambientales del bosque, con objeto de desentrañar los fines que persigue con este modelo de gobernanza. Bajo el horizonte analítico de la formación del Estado, documento un caso de estudio que revela dichos principios de resguardo territorial como una gobernanza instrumental cuyo fin es acrecentar beneficios económicos y políticos para el aparato gubernamental.

* Centro de Investigaciones y Estudios Superiores en Antropología Social, Unidad Peninsular. Dirección: Parque Científico y Tecnológico de Yucatán, Km. 5.5, Carretera Sierra Papacal - Chuburná Puerto, 97302, Mérida, Yucatán, México. Correo: angeleslopez@ciesas.edu.mx ORCID: https://orcid.org/0000-0001-6700$520 \mathrm{X}$

Nota de la autora: Agradezco al maestro Ricardo Fagoaga su colaboración para localizar archivos significativos para la elaboración de este documento, así como a los evaluadores, quienes brindaron sugerencias relevantes para mejorarlo. 
Palabras clave: política pública; gobernanza y manejo ambiental; políticas distributivas; rendición de cuentas.

\begin{abstract}
Environmental governance in Mexico has been mostly analyzed through emphasizing contentious actors and conflicts. Nevertheless, this perspective does not reveal the complex settings of environmental governance as regulatory framework for capital accumulation. In this article, I explain how the Mexican government arranged the conditions to stablish itself as the main actor and recipient of the program known as payments for ecosystem services of the forest. Through the state formation framework and over a case study, I try to reveal the real purposes behind this environmental policy, and how it works as an instrumental governance to attain and increase economic and political benefits for state power.

Keywords: public policy; environmental governance and policy; environmental management; distributive policies; accountability.
\end{abstract}

\title{
Introducción
}

La tendencia global de enverdecer esquemas y estructuras de gobierno es una estrategia geopolítica que catapulta los procesos de financiación prevalentes. En los últimos treinta años, el Estado mexicano ha reestructurado su organigrama institucional para edificar la gobernanza ambiental, y si bien algunos interpretan esta pauta como un aparente compromiso político (Lezama, 2010), considero que en realidad es resultado del interés del Estado para garantizarse el acceso a esquemas de financiamiento que potencian el robustecimiento de sus estructuras y el ejercicio de poder en su territorio.

De ahí que surjan las preguntas: ¿cómo es la relación inextricable entre las escalas de dominio hegemónico de los ámbitos supranacionales y nacionales que crean y recrean los marcos de regulación ecológica?, ¿cómo operan los instrumentos de gobierno ambiental en un Estado peculiarmente neoliberal y clientelar?, ¿cómo se dispersan e implantan estos esquemas globales en lo local y cuáles son sus resultados? 
Este documento ofrece un aporte antropológico al estudio de la gobernanza ambiental en México. Con base en el marco analítico de la formación del Estado, es decir, en el estudio de las relaciones dialécticas que forjan al Estado como entramado institucional, así como experiencia cotidiana desde abajo (Corrigan y Sayer, 1985; Joseph y Nugent, 1994), trazo la institucionalización de un modelo de gobernanza ambiental, el programa de servicios ambientales del bosque, ejecutado en un ejido del bosque tropical del Caribe mexicano. Desde un enfoque crítico, muestro la forma en que esta política ambiental ha sido instituida como mecanismo financiero de control político y social.

La gobernanza, grosso modo, se comprende como un modelo de gestión que se instituye en ámbitos tanto públicos como privados (Jessop y Sum, 2006). En términos político-administrativos, se explica como una respuesta a las condiciones de crisis de gobernabilidad manifiestas en el Estado neoliberal, como resultado de su ausencia o retiro parcial en campos políticos diferenciados, y cuyo fin es establecer condiciones de negociación y gestión multisectoriales. Como modelo político-administrativo, la gobernanza se ha explicado como forma de intervención multinivel, es decir, atendiendo a las condicionantes de verticalidad para su realización; pero también se ha analizado en la política pública como un mecanismo para consolidar pautas de horizontalidad y de gobierno más democráticas (Jessop, 2008), donde se promueve la gestión de recursos mediante la confluencia y la participación de diferentes sectores sociales para lograr acuerdos en la toma de decisiones en campos específicos (lo que algunos estudiosos han considerado como análisis de redes; véase Jessop, 2008; Bulkeley, 2005). Ahora bien, la gobernanza ambiental es la conducción de este modelo político-administrativo como entramado multinivel y multisectorial de acción social coordinada y enfocada en el medio ambiente y los recursos naturales (Lemos y Agrawal, 2006).

Si bien es posible abstraer los procesos de gobernanza ambiental desde diversos campos sociológicos, en México ha habido una tendencia a reducir el esquema analítico a una caracterización de actores que disputan en una arena (García-Frapolli, 2012; Flores, Aguilar, Reyes y Guzmán, 2018; Brenner y Rosales, 2015; Trench, Larson, 
Libert y Ravikumar, 2018). Asimismo, hay estudios que dirimen sobre las fallas para instituir el tipo ideal, que suponen que la gobernanza es como un campo político de coordinación democrática (Paz, 2012); mientras que otros estudios se orientan a describir las percepciones locales sobre la instrumentación de los modelos con el fin de entender algunos de sus resultados con fines pragmáticos (Perevotchikova, 2016; Trench et al., 2018). Si bien estos enfoques realizan aportaciones para su comprensión y realización, se observan serias limitantes, tales como entender la mencionada arena como epítome de la gobernanza; o bien, hay vacíos analíticos en lo que se refiere a cuestionar los modelos como política pública.

Asimismo, se han hecho pocos desagregados sobre la variabilidad de los modelos de gobernanza ambiental. ${ }^{1}$ Sin embargo, para el caso de los servicios ambientales del bosque, se ha dado un seguimiento a las variaciones que el Estado ha diseñado en los instrumentos de esta política sectorial. No obstante, los contenidos subyacentes del esquema y el ejercicio de poder en su implantación no siempre han sido interpelados (un ejemplo de esto son los estudios de Perevochtichikova, 2014b; 2016).

Considero pertinente atender los dominios institucionales y estructurales del diseño e instrumentación en los cuales la gobernanza ambiental se edifica como objetivo público. Esto implica integrar la explicación del modelo desde los principios político-económicos que lo edifican, los elementos ideológicos que lo justifican, los campos sociológicos que integra o atiende, las manifestaciones del poder, así como las consecuencias reales derivadas de su implantación en lo concreto. Todo con el propósito de conocer qué opera detrás de su ejecución (Smith, 2006).

Con base en el marco de la ecología política y con el ojo en un ejido de Quintana Roo, México, sugiero la pertinencia de observar los marcos de gobernanza ambiental como artificios regulatorios.

${ }^{1}$ Lemos y Agrawal (2006) explican esta variabilidad por los campos de integración social en los que inciden los modelos (el mercado, la comunidad y el Estado) y su relación con los incentivos e instrumentos de participación y vigilancia (estos últimos relacionados a los campos de integración). Reconocen la existencia de hibridaciones, ya que su aplicación "exitosa" depende de diversas variables. 
Retomo a Jessop y Sum (2006) para engarzar el enfoque de la regulación al análisis de la gobernanza, ya que el modelo aquí estudiado, los servicios ambientales del bosque, indica ser un instrumento económico contingente revestido de forma regulatoria, orientado a potenciar la reproducción del capital.

La teoría de la regulación (Lipietz, 1986, pp. 15-16) supone que el régimen de acumulación se cristaliza no sólo en los marcos macroeconómicos de la producción, la circulación y el consumo, sino también en los esquemas regulatorios que se expresan en distintos órdenes sociales (leyes, reglamentos, instituciones, incluyendo los que inciden en los marcos de la vida cotidiana) para garantizar la reproducción del sistema en su conjunto. ${ }^{2}$ Esto nos acerca a la necesidad de identificar además la confluencia de capitalismos y la condición multidimensional de los marcos de operación del sistema de acumulación (Jessop y Sum 2006, pp. 247-270).

Bajo dicho lente, el programa de servicios ambientales del bosque es analizado aquí como un modelo de gobernanza cuestionable. Si bien la noción de gobernanza ha incorporado las posibilidades de realizarse como un proceso político participativo e incluso democrático (Jessop y Sum, 2006; Brenner y Rosales, 2015), este programa revela ser un esquema económico en el que el Estado se erige como actor central para mediar, coordinar, tomar decisiones e institucionalizar un instrumento de gobierno ambiental. Apoyado en prácticas multidimensionales de selectividad administrativa, el Estado genera una política pública neoliberal para producir valores económicos bajo formas de apropiación simbólica y real de las relaciones e intercambios que se dan tanto en los ecosistemas, como entre la sociedad, el territorio y el medio ambiente. Asimismo, cristaliza la mediación político-económica de un modelo hegemónico global en las poblaciones y territorios "objetivo", bajo el paraguas de las prácticas sociohistóricas y socioterritoriales de su interrelación con los grupos subalternos.

El caso de estudio revela un ejercicio de gobernanza en el que el Estado se refuerza y renueva mediante instrumentos de reterrito-

${ }^{2}$ Los presupuestos de la teoría de la regulación son medulares al abordaje analítico del Estado como ensamble institucional idóneo para la reproducción del sistema capitalista (Jessop, 2008). 
rialización "productiva" fundamentados en esquemas financieros y monetarios controlados de forma vertical y centralizada. Dado que el modelo debe engarzarse como una estructura político-económica imbricada en los ámbitos institucionales "desde abajo", también favorece la reproducción relativa de valores relevantes en los entramados propios del sistema en general y del modelo en particular: monetización, especulación, cálculo y mercantilización de la naturaleza.

En última instancia, en la aplicación de este modelo el Estado encarna, mediante sus agentes institucionales, a un capataz que gobierna mediante coerción y coacción para la producción de valores económicos (servicios ambientales), mientras inscribe su soberanía en el paisaje. ${ }^{3}$

Mediante el caso de SinTunich ${ }^{4}$-una población sujeta a intervenciones para gobernar su porción de bosque tropical- se atiende a las paradojas de los esquemas neoliberales de capitalización de la naturaleza mediados por el Estado, al tiempo que se observan las estrategias y cálculos diferenciados que tienen lugar en las instituciones locales ante la ejecución de estos esquemas de política pública.

Para desentrañar el proceso, analizo el diseño de los instrumentos de Pagos por Servicios Ambientales (PSA) en los bosques mexicanos, esquema impulsado por el Banco Mundial (BM) y el Global Environmental Facility $(\mathrm{GEF})^{5}$ a través del gobierno mexicano y

${ }^{3}$ Aquí debo hacer un apunte extra. El Estado como estructura relacional y entramado institucional no se observa como bloque uniforme, mucho menos homogéneo, ni puede entenderse de forma unívoca. Como estructura de instituciones, depende de actores que median el poder institucional en contextos específicos bajo estrategias diversificadas (Jessop, 2008). El Estado como capataz hace referencia a la acción coordinada de los agentes de instituciones federales que median modelos de gobernanza globales, esquemas que coadyuvan a la reproducción del capital como sistema, pero, en el caso mexicano, consolidan beneficios político-económicos para la estructura de gobierno, lo que incluye a la clase política.

${ }^{4}$ SinTunich es un seudónimo, como otras denominaciones aquí referidas relacionadas a la localidad de estudio, debido a que los actores locales expresaron temor a las represalias de los agentes de Estado. SinTunich alude a la ausencia de costas verde esmeralda (Tunich), espacio donde se fija la idea de desarrollo y progreso en el Caribe mexicano.

${ }^{5} \mathrm{Al}$ final de este artículo se incluye un anexo con las siglas y acrónimos usados en este artículo. 
ajustado a los "principios" de la política nacional en su implementación (McAfee y Shapiro, 2010). Trato de tejer las relaciones significativas en distintas escalas, observando puntos nodales de este esquema de política pública: 1) el entramado de procesos de financiación como forma operativa del paquete neoliberal para la gobernanza ambiental como proceso multiescalar; 2) la revisión de las condiciones de su ejecución, incluyendo las cuentas públicas asociadas al programa nacional y su distribución en la región y en la localidad; 3) su instrumentación en lo local como monetización hacia abajo, como expresión de la dispersión del esquema financiero.

El caso permite dilucidar las condiciones anómalas de su aplicación y los mecanismos mediante los cuales el Estado extrae beneficios hacia su estructura. Como explicaré, el Estado se fortalece no sólo por su capacidad de ejercer de forma vertical la política pública, sino en función de su capacidad de apropiarse y explotar la mano de obra, así como de extraer valor de territorios y poblaciones para su propio beneficio y para la reproducción del capital. ${ }^{6}$

Este estudio se fundamenta en el análisis de fuentes documentales institucionales emitidas desde el Global Environmental Facility (GEF), el Banco Mundial y la Secretaría de Medio Ambiente y Recursos Naturales de México (Semarnat); así como desde los organismos desconcentrados de dicha secretaría: la Comisión Nacional Forestal (Conafor), la Comisión Nacional de Áreas Naturales Protegidas (Conanp) y la Comisión para el Conocimiento y el Uso de la Biodiversidad (Conabio). Otra fuente documental fue un conjunto de archivos recientes del ejido SinTunich, facilitado por las autoridades ejidales. Se obtuvieron datos de primera mano mediante técnicas etnográficas realizadas in situ, en donde realicé observación participante, análisis situacional, veinte entrevistas estructuradas a autoridades y ejidatarios de SinTunich, así como a otras autoridades ejidales de tres pueblos circunvecinos (durante una semana en 2015, en una estancia de cuarenta días de trabajo de campo en el verano de

${ }^{6}$ Recientemente, Gago y Mezzadra (2017), así como Mezzadra y Neilson (2019), han destacado la relación entre el extractivismo y la financiación, y el rol central del Estado para garantizar este nexo. Aluden a rubros diferenciados de la reproducción del sistema (monetización, deuda, generación de subsidios, entre otros). 
2017, y una semana en mayo de 2018). Todos los testimonios recolectados se obtuvieron mediante consentimiento informado y bajo anonimato.

\section{Los bosques de la nación: sitios reproductores de agua, biodiversidad y renta}

La valorización y la capitalización de la naturaleza se consolidaron como un proceso global en los años noventa con la dispersión del discurso del desarrollo sustentable. Este marco favoreció que los servicios ambientales se conceptuaran como fuente de riqueza, tendencia que se afianzó, particularmente en México y Latinoamérica, después del año 2000 (Perevochtchikova, 2014a).

Siendo el dinero un principio moderno y transformador en términos institucionales y sociológicos, el Estado, al definir los recursos naturales como capitales (Conabio, 2000), convirtió a los territorios en espacios fértiles para la financiación. En general, la política ambiental mexicana se ha desarrollado mediante el uso de préstamos y donaciones financieras del Banco Mundial y del GEF desde los años noventa, y su fin ha sido edificar políticas sectoriales, argumentando la necesidad de: (i) crear capacidades institucionales para desarrollar la gobernanza ambiental, (ii) diseñar el manejo estratégico de programas prioritarios que conduzcan a (iii) evitar la degradación de ecosistemas de interés; pero también se añade un componente central: (iv) erradicar la pobreza.

Desde 1992, estas rondas de financiamiento promovieron en principio el modelo de áreas naturales protegidas (ANP). En el mismo periodo, se reconoció una tasa de deforestación de $2 \%$ anual en los bosques del país (mesófilos, tropicales y de matorral). El riesgo para tales ecosistemas y sus servicios ambientales se bosquejó sobre la erosión de suelo, la reproducción de la biodiversidad, así como en el abastecimiento de acuíferos. La masa forestal (140 millones de hectáreas en 2007, según Conafor, citado en Merino 2012, p. 35), la mayoría bajo régimen de derechos ejidales o comunales $(70 \%$ según Muñoz-Piña et al., 2008), requirió una política sectorial, por lo que se dictó la Ley de Desarrollo Forestal Sustentable (LDFS) en 2003, 
como instrumento regulatorio y de manejo territorial. Esto facilitó la bifurcación de la política pública de los emergentes organismos desconcentrados de la Semarnat: Conanp y Conafor. El primero se orientaría a fortalecer las condiciones de oficialidad del Sistema Nacional de Áreas Protegidas (Sinap), mientras que el segundo ejercería control sobre los bosques. Conafor realizó el diseño del esquema PSA para atender el riesgo creciente de deforestación, pero también como mecanismo de rentas diversificadas para el Estado.

El relato de la creación de los mecanismos PSA en México puede ser identificado en fuentes específicas (McAffe y Shapiro, 2010; Alix-Garcia et al., 2005; Muñoz-Piña et al., 2008). Igualmente, existen fuentes que permiten comprender el avance en la instrumentación desde sus inicios hasta años recientes (Perevochtchikova, 2014b; 2016). Sin embargo, poco se ha discutido sobre las cuentas públicas que le dieron vida. El diseño y el acuerdo financiero para aplicar el esquema se encuentran detallados en una fuente no tratada anteriormente: la carpeta del proyecto del GEF y BM (s.f.), "Environmental Services Project P087038" y "Mexico Environmental Services Project P089171".? El análisis de esta fuente permite conocer la lógica de financiación en la que se edificó la política pública de arriba a abajo. Da luces sobre las condiciones en que se forja el proceso financiero nacional, lo que permite cuestionar las cuentas públicas del programa; asimismo, su análisis conduce a observar las condiciones anómalas de su institución en el lugar de estudio. Todo con el fin de dar otra perspectiva sobre la realidad que gira detrás de este ejercicio de gobernanza. ${ }^{8}$

Los PSA tuvieron antecedentes en 2003, en un diseño de programa piloto que cubría componentes prioritarios: bosques y agua. En 2003 y 2004 México le presentó al Banco Mundial y al GEF un diseño de proyecto de deuda de $\$ 81$ millones USD para dar continuidad a esos programas piloto (Pago por Servicios Ambientales Hidrológi-

${ }^{7}$ Esta carpeta está compuesta por 34 documentos distintos que se refieren a la generación e instrumentación de la política pública de 2003 a 2011 (GEF y BM, s.f.).

${ }^{8}$ Lamentablemente, la extensión de un artículo científico es un límite para profundizar en el análisis del discurso en la documentación contenida en dicha fuente. Aquí constriño los datos del esquema de financiamiento para dar seguimiento a su instrumentación y a las cuentas públicas recabadas. 
cos: PSAH; y Captura de Carbono, Biodiversidad y Sistemas Agroforestales: PSA-Cabsa). ${ }^{9}$ Desde entonces se hicieron negociaciones con las supranacionales, pero también con el aparato legislativo en México, con grupos del sector forestal y agropecuario, y con otras agencias federales para generar el marco operativo a nivel nacional. Todos estos ámbitos de negociación representaron puntos de inflexión en el diseño que hasta hoy opera: la inclusión del componente de combate a la pobreza; la definición de las formas institucionales para los fondos financieros del programa (Muñoz-Piña et al., 2008); así como la disputa por el futuro de dichos fondos, lo que ha generado la hiperfragmentación de la operación de Conafor para cada entidad federativa (Alix-Garcia et al., 2005).

En los borradores de propuesta se observan los criterios de la asesoría del BM:

Implementing financial mechanisms that capture the value of the environmental services of the forest, offers the possibility of testing out new partnerships between indigenous communities and ejidos, the private sector and various government agencies [BM Proposal for Block B: Mexico Enviromental Services of the Forest Project, 2003, p. 1, en GEF y BM, s.f.].

Pero esta expectativa de asociación productiva resultó ser una ensoñación. McAfee y Shapiro (2010) destacan que había "condiciones complejas" para desarrollar un mercado eficiente bajo los cánones del BM: la propiedad social de la tierra no facilitaba la formación de un mercado abierto de ofertantes de servicios ambientales y sus compradores o usuarios. El gobierno mexicano puso fin a dicha problemática, no sin la inconformidad del Banco Mundial y sus asesores. El Estado mantuvo la centralización de la operación del programa con un despliegue de patrimonialismo, corporativismo hegemónico, fundamentado en un interés económico-político que se devela en la pauta precautoria sobre las condiciones de un mercado abierto: una competencia abierta entre ofertantes habría sido caótica e inoperable

\footnotetext{
${ }^{9}$ Posteriormente, la política forestal se expandió con los mecanismos REDD+ (reducción de emisiones por la deforestación y la degradación).
} 
en términos administrativos; había una falta de nivel educativo de los ofertantes para navegar en las pautas de precios y subastas, y el Estado tendría confrontaciones ante un posible escenario de injusticia distributiva (Muñoz, 2008; McAffee y Shapiro, 2010, p. 594). Con un "todos somos mexicanos", se ratificó el corporativismo patrimonialista. Esta decisión fue estratégica para el bienestar del Estado, o bien, de la clase política: en un ámbito rural altamente contencioso, las instancias federales apostaron por un esquema distributivo oficial, centralizado y vertical, lo que en el campo político se capitalizaría de forma multifactorial.

Así, se generó un mercado virtual: la federación con Conafor al frente sería el intermediario entre los usuarios del agua -un sector privado que paga derechos de agua y un conjunto de instancias gubernamentales que concentra los dineros bajo leyes específicas en cuentas globales de los gobiernos federal, estatal y municipal-y los "productores" de los servicios ambientales. El mercado virtual derivó en un nuevo programa de subsidio que opera como transferencia monetaria condicionada (TMC) bajo la siguiente dinámica: Conafor sometería anualmente a concurso zonas "prioritarias" del país; definiría los precios por hectárea para resguardo; emitiría y resolvería los concursos, seleccionando entre los distintos competidores los beneficiarios con quienes contrataría los bienes territoriales bajo la promesa del resguardo para generar agua (y biodiversidad, como le preocupaba al GEF); asimismo, vigilaría los términos de la contratación in situ, y retiraría "el apoyo" bajo penalización a los posesionarios de la tierra que no cumplieran.

Pese a que el diseño cojeaba desde 2005, el contrato final con el Banco Mundial se firmó en mayo de 2006 y se hizo con un préstamo de \$45 millones USD y una donación del GEF de \$15 millones USD. La agencia implementadora sería la Conafor, y entre los objetivos del proyecto se definieron: cubrir el territorio fuera del Sinap para proteger la biodiversidad; fortalecer las capacidades de Estado; generar condiciones y mecanismos financieros para el resguardo de la biodiversidad; monitorear y vigilar el resguardo forestal y sus productos (que nunca logró cuantificar); y combatir la pobreza. El proyecto indica que se pagarían los servicios emanados de las tierras en propiedad privada, comunal y ejidal, situadas en áreas protegidas y 
no protegidas en diferentes regiones, aunque se fue expandiendo a zonas más empobrecidas.

La aprobación implicó que de los \$45 millones USD del financiamiento del BM, el $23.72 \%$ se dirigiría a costos de fortalecimiento institucional (Conafor), mientras que el 57.64\% cubriría los pagos de los contratos de PSAH; es decir, el grueso de la deuda comprada serviría para capitalizar el Fondo Forestal Mexicano (FFM) para pagar a los participantes de los programas. Asimismo, de los $\$ 15$ millones USD de donación del GEF, el 56.33\% iría al fortalecimiento institucional, 33.33\% (\$5 millones USD) a la generación de un fondo, $\mathrm{y}$ $10.3 \%$ a los contratos y donaciones de PSA ${ }^{10}$ Básicamente, la deuda y la donación capitalizó la cartera del proyecto para su continuidad. Además, la generación del fondo era la parte indispensable del convenio, puesto que el proyecto debía tener continuidad y garantizar su "robustecimiento". Así, se creó el Fondo Patrimonial de la Biodiversidad (FPB), con una parte equivalente provista por el gobierno mexicano, y como una subcuenta del FFM.

Aprobado por el Banco Mundial en 2006, el proyecto PSA terminó y fue evaluado en 2011, generando un reporte ejecutivo que detalla lo realizado. El caso de SinTunich ofrece detalles de la aplicación del programa, como se hizo a nivel nacional, pero con varias anomalías. En general, el proyecto de PSAH, tanto en sus propuestas como en el periodo de realización y su finiquito, fue considerado un modelo para América Latina (documentos diversos, GEF/BM, s.f.), como avance de las líneas neoliberales de capitalización y mercantilización de la naturaleza que sólo habían operado en menor medida en Costa Rica y El Salvador. ${ }^{11}$

${ }^{10}$ GEF Trust Fund tf056321, 11 de mayo de 2006. Global Environmental Facility Trust Fund Grant Agreement between United Mexican States and Nacional Financiera, S.N.C. and International Bank for Reconstruction and Development acting as an implementing agency of the GEF (GEF Trust Fund, 2006, en GEF y BM, s.f.).

${ }^{11}$ Según Perevochtchikova (2016), el programa PSAH de Conafor se hizo mundialmente famoso después de 2010, principalmente por su expansión territorial. Mi argumento aquí es que dicha expansión es una estrategia de poder del Estado para legitimarse y reproducirse a través de la dispersión de un subsidio. 
Como mencioné, el Estado estuvo obligado a generar un fondo que garantizara la "robustez" del programa a largo plazo. En las cláusulas del convenio GEF-BM-México, el fondo es el componente financiero que obliga a que la donación del GEF sea transparentada. El FPB formado en 2008 se convirtió en una entidad financiera dinámica para generarle rendimientos, pero es menos visible pues se encuentra dentro de la subcuenta del FFM. El Estado lo guardó en un banco privado nacional: Grupo Financiero del Norte (Banorte). Y, de acuerdo con Semarnat y Conafor (2013), el FPB operaría como un mecanismo de reinversión en diferentes escenarios para generar intereses:

La estrategia de capitalización implica la conformación de paquetes de inversión de las áreas [rubros] elegibles para pagos con estos recursos [...] cada paquete debe ser invertido a través del mandatario del FFM en opciones de inversión de bajo riesgo, pero con rendimiento garantizado considerando las salvaguardas aplicables. Los esquemas de inversión se harán en valores gubernamentales [Semarnat y Conafor, 2013, pp. 11-12].

Con el Banco Mundial se pactó no hacer uso de los fondos sino hasta el término del proyecto; para 2011, con el esquema financiero establecido, el fondo duplicó su haber a \$21.5 millones USD. ${ }^{12}$ Se ha usado desde entonces, pero al parecer sus emisiones se han mezclado principalmente con fondos concurrentes, lo que hace más opacas sus erogaciones al involucrar donaciones del sector privado y de otros niveles (o agencias) de gobierno. ${ }^{13}$

${ }^{12}$ Report ICR00002161. Implementation completion and results report on a loan in the amount of US $\$ 45.0$ million and a grant from the GEF trust fund in the amount of US\$15.0 million to the United Mexican States for an environmental services project (BM-GEF 2011, pp. 15, en GEF y BM, s.f.).

${ }^{13}$ Los fondos concurrentes son pactos de pagos por los servicios ambientales en los que confluyen "compradores"; se realizan a través de "fideicomisos". Los actores centrales son la federación (Conafor) y las comunidades, pero concurren los gobiernos estatales y/o la iniciativa privada para generar los montos de compensaciones específicas bajo convenios. Perevochtchikova (2016, pp. 31, 67) documenta un caso en el Ajusco, Ciudad de México, y hace referencia a la falta de liquidez del convenio establecido con una constructora nacional (Ingenieros Civiles Asociados, 
Esto sentó un precedente en el país. El objetivo del expresidente de la República, Felipe Calderón, era hacer de los bosques sitios rentables mediante los PSA, y definía la política forestal encaminada a ese rumbo (Calderón, 2009); por ello, en los informes finales del proyecto la preocupación era si tendría continuidad o no en 2012, ante la posible transición política en el país. Pero el problema no sería la continuidad, sino la transparencia. Si bien Conafor ha ido adecuando los instrumentos de política pública en los últimos años después de numerosas evaluaciones (Perevochtchikova, 2014a; 2016), y ha hecho el modelo de PSA flexible a la inserción del sector privado y a la recepción de "donaciones" (en los denominados fondos concurrentes), siempre sometiendo a competencia a los posesionarios de tierras, paradójicamente los flujos diferenciados de recursos y su inversión localizada no se transparentan en los informes anuales de las cuentas públicas de la institución.

\section{SinTunich en el Caribe mexicano}

SinTunich es una localidad maya hablante de menos de 280 habitantes (INEGI, 2010); está rodeada por otras localidades también maya hablantes, algunas de origen yucateco y otras quintanarroense. ${ }^{14}$ Los campesinos que dieron origen a SinTunich eran mayas yucatecos que llegaron en la década de 1950 para emplearse como jornaleros en la explotación del chicle. Ahí aprovecharon la oportunidad de las concesiones ejidales y adquirieron en 1962 una dotación oficial de 1440 ha de tierras de bosque tropical, misma que no fue parcelada ante las reformas a la propiedad ejidal a fines de los años 1990.

ICA). Lamentablemente, la autora no cuestiona ni explica los beneficios logrados por parte de la empresa constructora, ni en términos fiscales ni sobre la especulación ante los retardos del pago; mucho menos abunda en clarificar la información relacionada con la apropiación simbólica y real de los bienes producidos (agua) bajo este acuerdo.

${ }^{14}$ La diferencia de origen es enunciada por los propios sujetos; se sustenta en condiciones históricas de reterritorialización y de desidentificación ante los mayas rebeldes del territorio quintanarroense. 
Desde la formación del asentamiento, los pobladores se ocuparon en extraer chicle, producir durmientes de ferrocarril hasta entrada la década de 1990, y producir carbón vegetal (práctica hoy vedada, pero defendida por ser redituable y sostenible desde su perspectiva). $\mathrm{Su}$ forma de vida ha dependido principalmente de la agricultura de subsistencia con un sistema de rotación tumba-roza-quema, así como de la explotación de maderables y caza, pero sin silvicultura, como sucede en otros ejidos mayas quintanarroenses al sur del estado.

En los alrededores, la mayoría de los ejidos mantuvieron el carácter de propiedad comunal y no parcelaron el territorio, por lo que su explotación se rige bajo acuerdos colectivos. Asimismo, en estos ejidos se puede apreciar una territorialización múltiple en donde se identifican capas cartográficas diferenciadas con base en los usos colectivos del monte (selva). Estos usos reflejan pautas continuas y discontinuas de acuerdo a la vida social (prácticas ancestrales, ciclos agrícolas y ciclos de producción de mercancías diversas).

La vida en el bosque, el sitio en el que se recrea la identidad maya mediante el modo de vida, favorece un patrón de uso de espacios discontinuos. El primero es el de las mujeres, quienes no ingresan al bosque, sino sólo habitan el poblado. En el interior del bosque se establecen áreas discontinuas, como el monte alto, que es el manchón de selva alta, es decir, con especímenes mayores a $10 \mathrm{~m}$, principalmente de tipo perennifolia y subperennifolia; esta área, donde la selva es más densa y menos transitada, tiene como fin el aprovechamiento progresivo. Funciona como reservorio de especies de mayor tamaño y de mejor condición, principalmente para la explotación de maderas para la arquitectura vernácula de los mayas y/o para fines comerciales. Además, aseguran los ejidatarios, el principio es delimitar esa zona para aprovecharla progresivamente y para todos ellos; aunque también extraen maderas preciosas de forma clandestina. En términos rituales no hay usos específicos del monte alto, ya que la ritualidad se circunscribe en el suelo agrícola, en donde se negocia con las entidades del bosque; esto es, se ofrenda a seres supranaturales (mayas y cristianos) para el beneficio de la actividad agrícola; sin embargo, las actividades rituales son continuas en los límites y en el interior de los poblados, donde la vida humana se resguarda. 
El resto de las áreas del bosque en el polígono ejidal son susceptibles de aprovechamientos diferenciados, pero centralmente son destinadas a la explotación agrícola. Dependiendo de la temporalidad de su explotación como suelo agrícola, el monte es bajo, mediano o encañada. Las encañadas, o terrenos agrícolas, pueden ser usadas hasta por tres años para labranza y se dejan reforestar bajo su ritmo natural de diez a quince años, convirtiéndose en monte bajo o mediano. En sí, SinTunich cuenta con manchones de monte bajo y mediano en todo el ejido, lo cual ha sido evaluado para la aplicación de instrumentos de manejo forestal. La lógica de explotación del bosque para la agricultura no es propiamente definida por una estrategia colectiva, sino responde más a necesidades individuales que se negocian y vigilan entre ejidatarios e incluso avecindados, buscando respetar los tiempos de recuperación de los suelos.

Se identifican además capas de reterritorializaciones dirigidas mediante programas federales. Existen unos potreros para ganadería extensiva que fueron aprovechados de forma exitosa en los años 1990 para producir leche y quesos, que se comercializaban en la zona costera, aunque posteriormente, por corrupción interna en la empresa ejidal y de las autoridades regionales, la empresa se desmanteló. Asimismo, en años recientes se implementó el aprovechamiento estabulado de cabras, pero dicho programa no dejó huella en el paisaje pues básicamente el ganado fue consumido por los pobladores sin generar producción. Sin embargo, las capas de reterritorialización más evidentes emergen de los mecanismos de gobernanza ambiental impuestos por Conanp y Conafor, que, mediante infraestructura y racionalización del bosque, indican las acciones de Estado para instaurar esquemas de gobierno ambiental, reorientar las actividades y modificar los modos de vida.

\section{Articular la agroforestería en SinTunich: instituciones al servicio de las instituciones}

Con base en el marco relacional y dialéctico de la formación del Estado, apunto dos dimensiones sociológicas en donde se edifican condiciones que transfieren beneficios del gobierno ambiental del 
bosque tropical hacia el Estado mexicano mediante la instrumentación de PSA. Por un lado, las instituciones locales cimentadas en la propiedad ejidal no sólo son condiciones estructurales incorporadas y aprovechadas por los ejidatarios, sino también son estructuras organizativas que generan beneficios indirectos de la renta del bosque hacia el aparato estatal. Por otro lado, están los aspectos ideológicos engarzados al carácter propio de los subsidios, cuya aplicación y recepción resulta en la interiorización y uso de la "ayuda de gobierno", lo que incentiva la reproducción de relaciones de dominación mediante las cuales el Estado capitaliza los beneficios políticos y económicos. Describiré dos modelos de gobernanza ambiental conducidos hasta ahora en SinTunich para explicar las articulaciones que, desde abajo, trasladan valor hacia las instituciones de Estado; y planteo una reflexión sobre lo que representa el papel "de ayuda" del gobierno en poblaciones rurales con índices de pobreza.

\section{a) Gobernanza ambiental en México. Modelo I: reconfigurar la vida rural}

Desde fines de los años 1990, Semarnat garantizó la consolidación de programas de subsidios como estrategia para adherir adeptos a la conservación, lo cual Conanp fortaleció. SinTunich es un ejido que fue elegido para la aplicación del Programa de Empleo Temporal (PET) y del Programa de Desarrollo Rural Sustentable (Proders), hoy Procodes (Programa de Conservación para el Desarrollo Sostenible), así como de las Unidades de Manejo Ambiental para fauna o flora (UMA).

Los programas de Conanp funcionan como TMC, esquemas distributivos dirigidos al manejo ambiental, cuyo real objetivo es el combate de la pobreza. Mientras, en la retórica institucional el manejo ambiental supone la reconversión productiva hacia el sector terciario. Con estos instrumentos, Conanp ha hecho del turismo la actividad más relevante para la inversión "productiva" de TMC en las áreas protegidas y sus zonas de influencia (López, 2015).

SinTunich se encuentra en la zona de influencia de dos áreas de protección de flora y fauna (APFF) cercanas entre sí, aunque prote- 
gen ecosistemas diferentes y contrastan radicalmente en el número de pobladores, lo que impacta su regulación. Esta zona de influencia no se definió bajo criterios institucionales ni ambientales, sino discrecionales con base en la previa vinculación que el director de ambas áreas (gestión 2000-2010) tuvo con los grupos sociales de la zona en los años noventa (López, 2015).

SinTunich recibió los subsidios mencionados dado que se creó un circuito ecoturístico que denominaré "Keespiixan", el cual fue diseñado por la organización no gubernamental (ONG) que dicho director de área coordinó a fines de los años 1990. En este marco de dispersión de ideologías de conservación para el desarrollo sostenible -entiéndase desarrollo de ecoturismo-, SinTunich recibió de Conanp subsidios para reactivar un proyecto de oferta de hospedaje, $\mathrm{y}$ además generó otras ofertas turísticas.

El ejido SinTunich tuvo que formar una nueva cooperativa para recibir subsidios de Conanp, misma que está conformada hoy por 41 socios (33 ejidatarios y 9 mujeres). La cooperativa, que llamaré "Panal", trabaja bajo el modelo ejidal acostumbrado, es decir, todos aportan horas-hombre para el desarrollo de los proyectos. Las formas de colaboración para la empresa son dos: por turno y por fajina. La fajina es el trabajo colectivo coordinado para la generación y el mantenimiento de la infraestructura (cabañas, brechas, espacios públicos, entre otras cosas) y es realizado sólo por los varones. El esquema de turnos rotativos funciona principalmente en la administración de la cooperativa, en la provisión de servicios turísticos (guías de turismo, sólo varones), así como entre las cocineras y lavanderas.

Entre 2001 y 2006 la oficina de Conanp erogó \$21 400 USD a la cooperativa ejidal Panal para la infraestructura de servicios de hospedaje, la capacitación en turismo a los miembros de la cooperativa, y el equipo para actividades de turismo de naturaleza. A eso se sumaron \$6000 USD destinados para dos UMA en el lugar, lo que benefició solamente a dos familias, y \$3900 USD para pagar los estudios técnicos a empresas u ONG que se enfocaron en el "rescate" de las tradiciones locales. ${ }^{15}$

${ }^{15}$ Reportes de avances físicos y financieros de metas, 2001-2006, Semarnat y Conanp, www.conanp.gob.mx (consulta: abril de 2009). 
No obstante, a partir de 2006 Conanp canceló la distribución de los subsidios para los proyectos en las áreas de influencia, aunque apuntaló un solo proyecto al norte del estado; esta decisión fue cuestionada por el resto de los grupos, dada la evidente discrecionalidad en el reparto de los apoyos. En el contexto de otra investigación, en 2007, indagué sobre el futuro de los colectivos participantes del circuito ante la reorientación de Conanp para distribuir los financiamientos Proders / Procodes, que redujo por presupuesto federal y dirigió a intereses no clarificados. Ante la incógnita sobre el futuro complejo de estas localidades, el exdirector de las APFF analizadas dijo: "a ver qué hacen, no es problema mío". Eran evidentes los lazos de dependencia, subordinación y paternalismo en la constitución del circuito; asimismo, la falta de flujos de las TMC para impulsar las empresas las dejaba endebles y con muchas incertidumbres sobre la reproducción futura. La expresión de indolencia del funcionario fue pasmosa ya que los proyectos los traducen en cifras oficiales: estadísticas para justificar erogaciones y demostrar avances en materia de manejo ambiental y de impacto social en el "avance contra la pobreza".

Conanp dejó el escenario en un momento crítico: en 2006 se implementaron vedas para las quemas necesarias para la agricultura itinerante a causa de los huracanes Emily y Wilma de 2005, pero se extendieron por cinco años consecutivos. Esto generó ajustes en la economía de SinTunich, y aun cuando al parecer no todos respetaron las vedas establecidas, hubo movimientos pendulares de algunos jefes de familia y jóvenes hacia la costa turística para garantizarse ingresos. Otros programas de TMC, como Prospera (antes Oportunidades) y Procampo, los mantuvieron a flote. Afortunadamente para SinTunich, la expansión del turismo internacional favoreció el incremento de los flujos turísticos en 2012. ${ }^{16}$ Para 2015, la cooperativa Panal pudo establecer ganancias continuas para los socios, y volvió a garantizarse subsidios de la Comisión de Desarrollo para los Pueblos Indígenas (CDI) para el proyecto de ecoturismo indígena.

Con el repliegue de Conanp en 2006, la presencia de Conafor se fortaleció para dar continuidad con un esquema distinto de go-

${ }^{16}$ Entre 2011 y 2015 los arribos internacionales se incrementaron $21 \%$ a nivel global; véase https://www.cbd.int/cop/cop-13/hls/tourism-hls-en.pdf 
bernanza ambiental: contratos de pagos por servicios ambientales. Conafor es una institución con mayor fortaleza, más presupuesto y mayor burocracia que Conanp, por lo que el peso del Estado tuvo un reflejo peculiar en SinTunich.

\section{b) Gobernanza ambiental en México. Modelo II: coordinación institucional para mercados selectos}

La sinergia institucional entre Conanp y Conafor es significativa y reveladora como estrategia territorial para edificar el gobierno ambiental coordinado por el Estado. En la zona, Conanp desbrozó el camino para la formación de adeptos a las TMC de gobierno ambiental. Esto facilitó la movilización de recursos y voluntades para instrumentar los PSA en SinTunich por medio de Conafor. La estrategia de esta comisión llevó más tiempo, y se realizó bajo múltiples contradicciones y evidentes ajustes del modelo a aplicar.

Conafor, en contraste con Conanp, trabaja centralmente con los posesionarios de la tierra (ejidos, ejidatarios con parcelas delimitadas y propietarios privados). El ejido se convierte entonces en la institución eje con la cual Conafor se coordina hacia abajo para inscribir las estrategias territoriales que el Estado mexicano y el BM han generado para proteger bosques, agua y biodiversidad: modelos de agroforestería para el mercado de servicios ambientales. ${ }^{17} \mathrm{El}$ armado institucional de estos instrumentos es una vuelta de tuerca de los modelos de gobierno territorial entrelazados íntimamente en la estructura ejidal para capitalizar el bosque, extraer renta y justificar la gobernanza como esquema participativo.

Entre las condiciones para generar los servicios ambientales, se precisa la legibilidad territorial (Scott, 2013): clasificar y cuantificar la superficie de bosque, sus características y sus especímenes, como

${ }^{17}$ La agroforestería se hizo casi una ordenanza de política pública con el paso del tiempo. El Programa Nacional Forestal 2014-2018 establece que se han de promover modelos de agroforestería con fines de reconversión productiva, lo cual dirige la reconversión para la ejecución de los PSA (Diario Oficial de la Federación, 28 de abril de 2014, www.dof.gob.mx). 
entidades generadoras de servicios no mensurables, pero valiosos y necesarios para "la sociedad mexicana". Bajo este esquema, el Estado, a través de Conafor, cuantifica, califica, coordina, dirige, vigila y castiga, cuando es el caso, la forma en que el territorio forestal se maneja bajo estos contratos.

Desde 2004, periodo en que Conafor comenzó a coordinarse a nivel estatal, SinTunich fue evaluado para identificar su potencial para los PSAH. Entonces se diagnosticó que no era elegible, a pesar de estar en la zona definida como alimentadora de acuíferos. Sin embargo, la presencia de Conafor a partir de 2006 fue sustancial para conducir gradualmente tal posibilidad, pues aplicó la misma estrategia relacional de Conanp para forjar escenarios factibles mediante la elaboración de un conjunto de talleres participativos para el manejo de recursos. Tales talleres condensaron prácticas y conocimientos de la zona que, al ser retransmitidos por "expertos", acreditaron los marcos socioculturales indígenas de manejo ambiental en el discurso institucional y científico para alentar su reproducción: apicultura, formas de reproducción de semillas (externas y nativas), aprovechamiento del solar doméstico (huerto), aprovechamiento de los conocimientos de herbolaria, entre otros. En estos talleres se incorporaron las mujeres: se elaboró un proyecto para la Unidad Agrícola Industrial de la Mujer (UAIM), figura sujeta a la asamblea ejidal, para realizar mermeladas de frutos tropicales. Aun cuando dicho proyecto está en espera de reactivarse, un par de mujeres han canalizado el capital social y cultural para insertar sus productos artesanales en los mercados verdes de la región.

Pero la "construcción de capacidades" de Conafor se materializó posteriormente. Uno de los parámetros que establecen las condiciones para la aplicación de los instrumentos monetarios de PSAH -y otros forestales- es la edificación del Ordenamiento Territorial Comunitario (OTC). ${ }^{18}$ En ese periodo, el OTC y los ordenamientos a otras escalas territoriales (municipales y estatales) se consideraban instrumentos de regulación territorial eficientes para orientar

${ }^{18}$ Como mencioné, los procesos de transferencia de tecnología, información, certificación y seguimiento en lo local fueron incluidos en el paquete de instrumentación de los mecanismos PSA en el proyecto ante el GEF y el BM. 
la productividad y el aprovechamiento de los recursos con criterios de sustentabilidad. El OTC de SinTunich fue pagado por el ejido a través de un subsidio de Conafor y se realizaron los estudios durante 2008 para ser instituido en el acta de asamblea en noviembre de ese año.

Las condiciones en que se realizan estos instrumentos de gestión territorial son sintomáticas del modelo neoliberal en la administración pública. La Comisión define una lista de especialistas y técnicos aprobados en materia forestal para realizar los instrumentos de legibilidad territorial bajo los esquemas del instituto, incluyendo los cartográficos. De esta manera, bajo un modelo de subcontrartación (outsourcing), la Comisión eroga los dineros mediados hacia los ejidos para pagar a los técnicos reconocidos que desarrollan los parámetros de incidencia socioterritorial. Los técnicos, como empresas particulares, pueden cumplir o no con los contratos realizados. ${ }^{19}$ En el caso de SinTunich, explican, el OTC no se realizó satisfactoriamente: el ejido no recibió la documentación completa, pese a haber pagado.

No obstante, hay indicios significativos del borrador de OTC, al que tuve acceso. El documento revela un diálogo entre los técnicos forestales y la comunidad al incluir las actividades que, desde las generaciones precedentes, se han realizado (aprovechamiento forestal para maderas, para carbón vegetal, agricultura itinerante, caza, apicultura), así como las más recientes, como el ecoturismo y la extracción de insectos vivos que se venden en Cancún. Esto muestra la necesidad de reconocer el territorio como un medio integral para el modo de vida comunitario, aunque se privilegia el ecoturismo, dadas las expectativas sobre ello. También se observa el énfasis institucional para establecer las fajinas y otros "usos y costumbres" como formas de coordinación interna.

Pero hay contradicciones: el documento inicia destacando que SinTunich no es elegible por Conafor para los mecanismos de PSAH,

${ }^{19}$ Lo que implica además riesgos de corrupción y discrecionalidad en la distribución de los dineros del programa. "La Estafa Maestra", una investigación periodística que ganó el premio Ortega y Gassett en 2017, documentó cómo instituciones federales y estatales en México usan modelos de outsourcing para desviar recursos mediante contratos con empresas fantasmas o que realizan los trabajos a costos altísimos. Véase https://www.animalpolitico.com/estafa-maestra/ 
después se contradice y afirma que sí, y finaliza señalando que el área forestal de reserva del monte alto (la zona más arbolada) no es susceptible para integrarse en los PSAH. Esto deja interrogantes serias sobre el tipo de superficie que se elige, pues originalmente el programa condiciona su aplicación a porciones terrestres con $70 \%$ de cobertura forestal. La interrogante se agranda pues Conafor cambia año con año las zonas elegibles en las cuencas a concurso: se alegan restricciones presupuestarias, pero también con ello el esquema se expande y se "distribuye" estratégicamente en el territorio nacional.

En general, la normativa y los documentos técnicos que garantizan los contratos son puntos de tensión entre las autoridades y los representantes ejidales. Cuando sale a relucir que el OTC no está en regla, los ejidatarios de SinTunich les recuerdan a los de Conafor sus esquemas inoperantes de outsourcing. El aura de corrupción que sostiene Conafor en casi todo el país, que incluso recalcan sin titubear agentes de otras instituciones federales, ${ }^{20}$ son elementos que los ejidatarios usan para confrontar y negociar con los agentes de Estado las condiciones de desventaja que desde ahí se generan.

En 2011 SinTunich concursó por un PSAH, con el cual fue favorecido. La zona se delimitó, sintomáticamente, en un área encañada, tierra agrícola sin masa arbórea cercana a los límites ejidales. Esta superficie de 200 ha sería sometida al convenio, el cual además asignó a los ejidatarios un patrón de reforestación. El instrumento se aplicó distinto: los PSAH se supone comprometen área arbolada que no habrá de explotarse en cinco años (Merino et al., 2005; Madrid, 2011). En 50\% de las 200 ha de SinTunich no había árboles y se estableció un patrón de reforestación con especies de la zona (principalmente cedro y caoba), lo que indica la aplicación de un modelo de fondos concurrentes con la entidad federativa (Quintana Roo). Esta aplicación en sí estuvo condicionada al cumplimiento de un esfuerzo de trabajo bastante significativo. Se hicieron brechas cortafuegos; se realizó limpieza del predio, así como plantaciones de reforestación trazadas como retícula en un espacio relativamente pequeño, bajo los requerimientos estipulados para dos especies arbóreas. Finalmente,

${ }^{20}$ Relatos obtenidos de junio de 2017 a febrero de 2018 en conversaciones informales con tres agentes de instituciones federales en la región. 
dicha porción debía estar reservada por cinco años. Su ciclo inició en 2012 y finalizó en 2017.

Por esas 200 ha resguardadas, la Conafor pagó al ejido SinTunich $\$ 40000$ USD, y se repartió a los ejidatarios un promedio de $\$ 1000$ USD a cada uno en los cinco años. El grueso del trabajo se realizó al inicio, y los pagos se efectuaron hasta el tercer año. Lo que resulta significativo es el monto tan básico por la superficie resguardada bajo un esquema de pago en el que no hay una reevaluación del producto acumulado del trabajo social en los siguientes años después de su resguardo, ni de los precios del producto que el Estado vende (agua). Es decir, el Estado fija un precio específico por hectárea bajo contrato de cinco años de resguardo y lo deroga en tres, apropiándose de los pagos de los usuarios de los servicios ambientales y de los incrementos en el precio del servicio, no paga el trabajo de reforestación, además de que favorece sus finanzas con la acumulación de los intereses de los fondos forestales, los cuales capitalizan los bancos privados.

Los ejidatarios de SinTunich conceptualizan el poder de organizar esta producción con un giro de significado, definiéndolo como ayuda o apoyo dada la mediación del Estado para pagar en dinero contante y sonante: un bien escaso en la forma de vida de una sociedad indígena marginal. Los técnicos del Estado llaman apoyo al subsidio; pero visto desde abajo como ayuda, supone una aceptación de limitaciones inherentes al lugar para generar productividad. Así, la idea de ayuda reifica las condiciones reales y materiales de estas limitaciones, coadyuvando al esquema de dominación. El problema más básico es que el esquema de pago lleva un contenido de injusticia poco evidente para los participantes: su trabajo es visto como un esfuerzo extra en una obligación contractual a cambio de un pago "mayor" por responsabilizarse en compromisos de resguardo; el trabajo no lo observan como valor, sino como esfuerzo secundario con el fin de desahogar los gastos en un marco de escasez prevalente. Si bien hubo especialistas que alertaron que el instrumento terminaría como un subsidio y como un esquema de TMC (Alix-Garcia et al., 2005; Merino et al., 2005), también arguyeron que las sociedades locales terminarían gozando de la renta del bosque por los subsidios. Sin duda, se olvidan de la alienación del producto acumulado, y de 
quién en realidad se apropia de la renta de los bosques, de los fondos fiduciarios del FFM y del FPB, y del trabajo de los campesinos.

En 2015, SinTunich se postuló a un segundo programa de subsidio, al igual que otras localidades a su alrededor, pero sólo ésta fue aprobada con recursos. Tal programa se denomina Compensación Ambiental por Cambio de Uso de Suelo en Terrenos Forestales (CACUSTF), y aun cuando es un esquema distinto a los PSAH, su objetivo es edificar el perfil para PSAH, además su financiamiento se deroga del FFM de la misma manera.

El CACUSTF tiene como objetivo la restauración de suelos a través de un ejercicio de reforestación. De nuevo, la aplicación que hizo Conafor es cuestionable: se realizó en una zona de monte bajo, y se hicieron plantaciones en un polígono relativamente arbolado. SinTunich recibió por 100 ha de reforestación un aproximado de \$79 400 USD, y cada ejidatario obtuvo un promedio de \$2 300 USD diferidos a tres años, aunque el compromiso de resguardo fue por cinco. El CACUSTF obliga al trabajo en el monte, el cual fue realizado por los ejidatarios también mediante fajinas. Las 100 ha fueron distribuidas entre los 33 ejidatarios en una retícula trazada en la superficie pactada y en la que cada ejidatario trabajó hasta tres hectáreas. Este trabajo implicó la formación de brechas cortafuego en el perímetro, y en cada porción de labranza cada ejidatario realizó deshierbe y desmonte de algunos especímenes, recolectó madera y la transfirió a una zona de acumulación para fines imprecisos (aunque supone removerla ante riesgos de incendios), trasplantó semillas y se encargaría de mantener la zona desbrozada para que el germinado de árbol creciera (cedro y después frutales). Aquí la condición del pago es que crezca la semilla, de lo contrario no se aplica el subsidio del siguiente año. Con ello, el Estado transfiere el riesgo de la inversión de forma plena a los participantes: Conafor define dónde se debe comprar las semillas, lo cual, según los ejidatarios, generó incertidumbre pues no las identificaron como las idóneas para su plantación. Al interrogarles sobre las condiciones de aceptación de una apuesta incierta, aseguraron: "es como un gancho... si cumples, tienes oportunidades después". ${ }^{21}$ Cumplir el contrato para garantizar

${ }^{21}$ Ejidatario de SinTunich, 30 de julio de 2017. 
el subsidio y para edificar la posibilidad para el siguiente. El interés, reitero, se centra en el cálculo de la incertidumbre de la liquidez monetaria. "El dinero es ayuda".

Los líderes ejidales, que son los responsables de la transferencia de los pagos una vez que Conafor erogó los montos acordados, se encargaron de coordinar el trabajo comprometido, y en general, aunque con discusiones entre ellos, todos los ejidatarios realizaron el trabajo asignado. Las fajinas en SinTunich son prácticas consuetudinarias de trabajo coordinado que operan como un compromiso (obligación) común para y por la propiedad ejidal; así, explican, se mantienen los beneficios colectivos restando incertidumbre a lo individual. Por ende, las fajinas, como la propiedad social, son formas instituidas para mantener una equidad en la distribución de los costos y los beneficios del trabajo conjunto en el poblado, cualesquiera que sean los objetivos colectivos. La labor de los líderes ejidales semeja una miniaturización de la vigilancia del Estado (Scott, 2013), dada la presión ejercida para el cumplimiento de la normativa interna; la no realización de las labores deriva en disputas cara a cara y en la amenaza de retención del pago. Pero, en general, los ejidatarios de SinTunich necesitan el efectivo, por lo que, aun cuando haya autoridades ejidales demandantes, esto es en realidad parte del juego ya que todos colaboran para obtener los beneficios individuales y colectivos.

Sin embargo, este esfuerzo de coordinación y cooperación es un mecanismo mediante el cual el Estado extrae beneficios que el aparato gubernamental aprovecha de forma multidimensional. Este caso sería un buen ejemplo de la noción expandida de extractivismo sugerida por Gago y Mezzadra (2017). Los autores explican cómo operaciones abstractas alimentan el predominio de lo financiero con bases territoriales:

[...] el capital financiero extrae valor de actividades, formas de cooperación y de obligaciones futuras de trabajo, mientras el Estado es garante de esto [...] se generan nuevas formas de empleo, y [el capital financiero e incluso el Estado como mediador o garante] extraen valor de la vitalidad social y la cooperación que [estos aparatos] no contribuyeron a forjar [Gago y Mezzadra, 2017, pp. 581, 583]. 
Así, las instituciones locales están al servicio de las federales, como Conafor, que en un rejuego de interés explota el trabajo de los campesinos pagando al mínimo los precios por hectárea. El capital financiero lo circula en mercados financieros rentables y retiene las ganancias de los fideicomisos (FFM, FPB). Asimismo, los pactos desde abajo le sirven para enumerar acciones del supuesto cumplimiento de sus programas financiados previamente por el BM; esto en un Estado con una burocracia creciente y corrupta.

Pero hay otros beneficios para el Estado mexicano que se revelan en las cuentas públicas de los programas ambientales/sociales. En el Cuadro 1 se muestra un comparativo entre los fondos contenidos en el FFM y lo que Conafor ha erogado en los programas. El desfase es notable ya que, según la Unidad de Transparencia de Conafor que brindó los datos, todos esos dineros del FFM se erogaron, mientras que la información expuesta en la página de internet de esta Comisión muestra montos distintos. La dispersión de programas de fondos concurrentes genera más problemas para la transparencia, pues puede haber donaciones de la iniciativa privada, las ONG y otras agencias de gobierno que no se revelan en las cuentas públicas de los programas. Así, en 2016 campesinos del país alertaron sobre la falta de pagos de Conafor y exigieron transparencia del FFM por posibles desvíos sobre los intereses generados en éste. ${ }^{22}$

Conafor fungió como capataz en SinTunich, con el programa de PSAH, pero durante la CACUSTF su vigilancia se redujo. Delegó prácticamente las condiciones del diseño en los técnicos contratados, aunque dictó dónde se comprarían los germinados y dio las indicaciones de su siembra. Asimismo, hizo una primera vigilancia del término del proceso, pero la segunda no la había realizado a mediados de 2017; ello frenaba el segundo pago para los ejidatarios, por lo que los líderes gestionaron que se realizara la segunda visita. Ante la negativa continua de la oficina regional, los líderes ejidales amenazaron con contactar a los representantes federales en las oficinas centrales en Jalisco. Quintana Roo es una entidad federativa con dos exgobernadores en la cárcel y niveles de corrupción altísimos, y los

${ }^{22}$ Véase https://www.animalpolitico.com/2016/03/la-comision-forestal-retieneel-presupuesto-e-intereses-de-programas-ambientales/ (consulta: abril de 2018). 
ejidatarios de SinTunich no estaban dispuestos a perder la apuesta. Después de la amenaza, la oficina regional ponderó su siguiente visita y autorizó el siguiente pago. Los campesinos de SinTunich refieren estas interacciones de desigualdad y de uso del poder como algo más que una molestia: no sólo son injustas, sino que no dignifican su trabajo y condición social.

\section{Cuadro 1}

Comparativo de montos monetarios del Fondo Forestal Mexicano frente a las erogaciones de Conafor, 2003-2017 (pesos MXN)

\begin{tabular}{lrc}
\hline $\boldsymbol{A} \tilde{\boldsymbol{n}} \boldsymbol{o}$ & $\boldsymbol{F F M}$ & $\boldsymbol{C}$ Conafor \\
\hline 2003 & 155114896.67 & - \\
2004 & 798054381.91 & - \\
2005 & 1183116047.91 & - \\
2006 & 1806925904.56 & - \\
2007 & 3860331688.23 & - \\
2008 & 5523886341.71 & 2690856580.00 \\
2009 & 7090612386.26 & 2812777595.00 \\
2010 & 7878212738.96 & 5729747393.00 \\
2011 & 7997842828.38 & 4605353155.00 \\
2012 & 7602078335.90 & 4595427899.70 \\
2013 & 8837778847.96 & 4184802625.20 \\
2014 & 8445810563.39 & 4846319567.47 \\
2015 & 7783687156.40 & 2182920115.00 \\
2016 & 8197510543.11 & - \\
2017 & 7252501809.02 & \\
\hline
\end{tabular}

Fuente: La información de la columna del FFM se obtuvo como respuesta de la Unidad de Transparencia de Conafor. Las erogaciones de Conafor se encuentran en los informes de ProÁrbol y Pronafor, en www.conafor.gob.mx (consulta: noviembre de 2017).

Pero los testimonios de la zona llevan a observar otra selectividad por parte de la Comisión: algunos ejidos vecinos postularon y fueron aprobados, pero sin recursos. Esto refleja una hiperfragmentación del territorio arbóreo sin un esquema coherente de planificación para garantizar el manejo territorial, lo cual fue también observa- 
do por otros analistas del PSAH (Madrid, 2011; Perevochtchikova, 2014b; 2016). A modo de hipótesis, bajo el conocimiento de la zona, considero que otras localidades cercanas no recibieron el subsidio puesto que poseen una producción turística mucho más rentable (Conanp dejó de apoyarles desde antes por la misma razón). Son ejidos con mayor superficie y poseen espacios de resguardo de monte alto, al que respetan con mayor interés debido a que lo han mercantilizado; además, han dejado la agricultura itinerante por su tránsito al turismo. Si toda la zona ha sido catalogada como viable para dichos programas, la única razón por la cual no son beneficiarios de Conafor, más allá del límite presupuestal, es que han sido considerados fuera de los límites de pobreza, lo que no es el caso de SinTunich.

En este sentido, en el reparto desigual de los programas mencionados se alertan anomalías serias. Conafor, al igual que Conanp, reproduce también desigualdades con sus programas: según los informes de los beneficiarios en general, se han pagado a parcelas individuales en tierras ejidales, así como a propietarios privados, los mismos montos que recibió SinTunich (también por 100 ha). Pero igualmente se observan predios menores con pagos con precios por hectárea más altos en la misma zona. No corroboré el trabajo realizado en otros sitios, por lo que ignoro si el esquema condicionado se aplica con la misma cantidad de mano de obra. Esto conduce a cuestionar la justicia distributiva del corporativismo patrimonialista, así como la discrecionalidad en el reparto de los subsidios y la racionalidad de crear un mercado virtual controlado por el Estado con un costo altísimo en burocracia.

Hay otra cuestión entonces que subyace en la evidencia de las cuentas públicas. La racionalidad del mercado virtual apunta a otras formas de control en una lógica distinta a la del manejo ambiental: se identificó una distribución de erogaciones que sugiere el manejo político de los recursos monetarios del FFM. En el Cuadro 2 se destacan los montos de inversión destinados a todos los programas de ProÁrbol, después denominado Pronafor, que a nivel nacional proveen servicios técnicos especializados, esquemas de PSA y de restauración, asociados con germoplasma y saneamiento. En dicho cuadro puede observarse la disparidad del gasto nacional con el estatal y el que finalmente llegó a SinTunich en los años mencionados. Pero en el tra- 


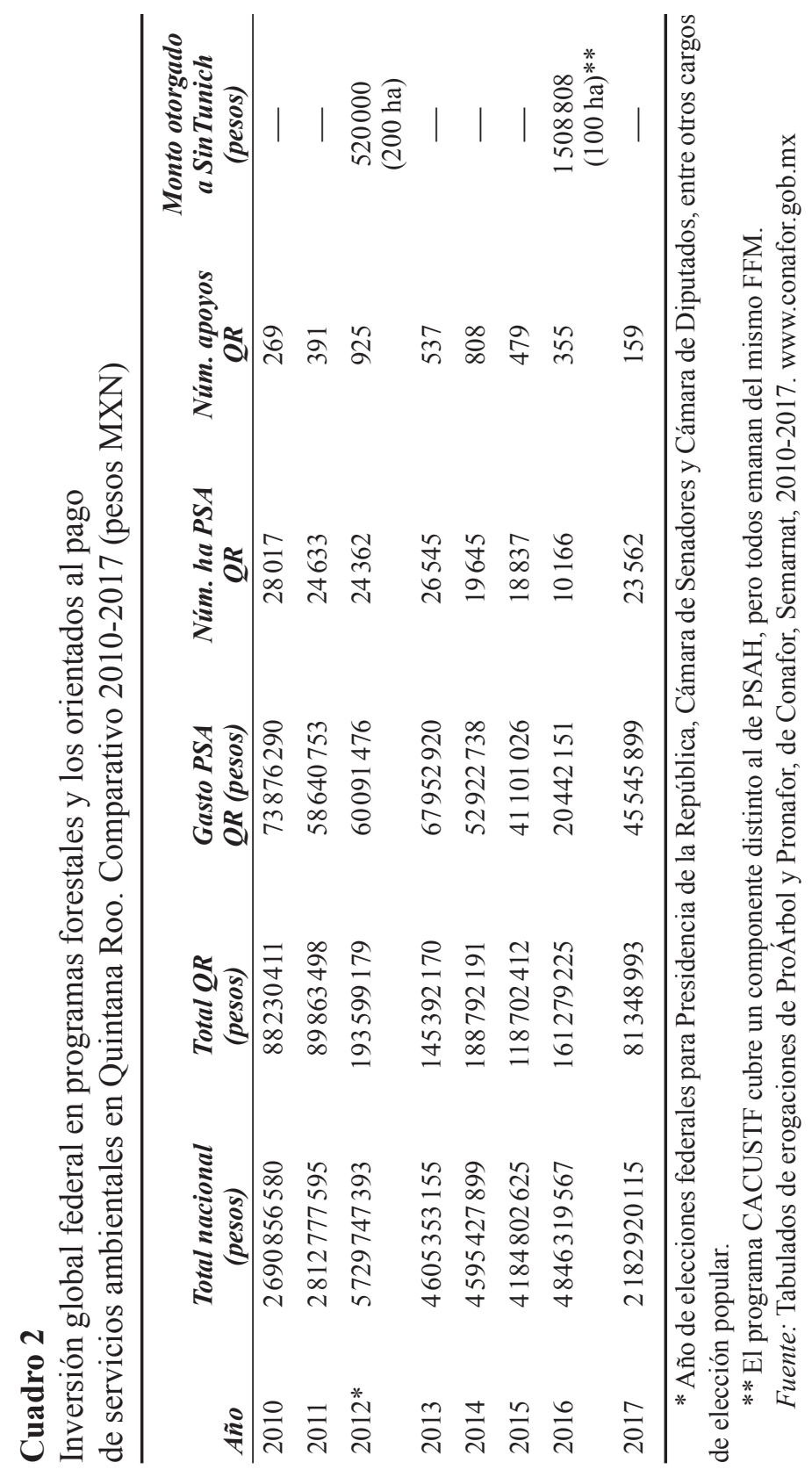


zo histórico se evidencia cómo en 2012, año de elecciones federales, se duplicó el gasto de inversión en programas para manejo forestal a nivel nacional; lo mismo sucedió en el estado de Quintana Roo, que además triplicó el número de beneficiarios en PSA. En 2012, SinTunich recibió el primer pago con un esquema PSAH implementado de forma atípica. El gasto de Conafor en ese año electoral federal revela una racionalidad conocida en el ámbito rural: la reproducción de los mecanismos del Estado mediante subsidios para manipular el campo político y la posibilidad del voto. El corporativismo y el clientelismo político deben redituarle de muchas maneras a un Estado que se distingue por su alto nivel de corrupción.

\section{Cierre: gobernanza ambiental, ¿instrumento financiero o mecanismo de control político?}

La gobernanza ambiental, vista como orden de estructuración favorable para la reproducción del capital, devela los mecanismos de apropiación y extracción de los beneficios en los mercados verdes. He tratado de apuntar hacia un conjunto de operaciones (Mezzadra y Neilson, 2019) que el Estado mexicano entreteje desde las porciones territoriales para consolidar el proceso de financiación como vía de reproducción del capital a través de un programa de política sectorial que opera como subsidio: la capitalización del Estado mediante deuda y donaciones adquiridas por medio de supranacionales; la implementación de los mecanismos financieros como fondos fiduciarios, insertos en bancos privados, que favorecen la circulación y la especulación de los valores financieros; así como el ejercicio de manipulación de presupuestos federales y bienes financieros en un mercado virtual en el que el Estado coordina pactos para la monetización hacia abajo, como medio de apropiación de bienes territoriales y trabajo para generar valores para la especulación futura. Así se ha materializado este paquete de política ambiental, además de su clara opacidad en la rendición de cuentas. Hay que mencionar que se pensó un paquete completo que redondea un proceso de financiación (Lapavitsas, 2013); éste se plasmó en la visión presidencial en 2009 (Calderón, 2009), cuando se proyectó la inclusión de créditos "blan- 
dos" del Estado para que los posesionarios de los bosques generaran plantaciones forestales. Pero dudo que SinTunich pudiera solventar una deuda para dicho fin.

Los esquemas PSA analizados ofrecen indicios para reevaluar los modelos de gobernanza ambiental como los instrumentos financieros que sugieren ser. Es decir, en este esquema la regulación de las relaciones socioambientales se concreta mediante un mecanismo contractual en donde se asegura un bien valioso (un bien territorial específico), se otorga un precio ficticio sobre sus posibles productos (servicios ambientales) en un mercado virtual en donde no conocemos el valor acumulado ni los procesos de financiación de los capitales que giran en los fondos fiduciarios, pero tampoco hay una rendición de cuentas sobre la producción esperada. Observar la gobernanza como un instrumento financiero nos acerca a las formas complejas en que el riesgo (deforestación por costos de oportunidad del uso de la tierra boscosa) y el resguardo ambiental se materializan con fines de explotación, extracción y manipulación financiera (Fairhead, Leach y Scoones, 2012). Desde luego, la gobernanza vista como instrumento financiero, como cualquier otro, requiere de un marco político-legal que lo facilite, que lo coordine, pero también que lo adapte a un esquema discursivo que favorezca su realización, y es el manejo del riesgo (cuencas en desecación, deforestación, cambios de uso de suelo y pérdida de biodiversidad) el hilo conductor que el Estado usa para el relato, y la pobreza como medio para consolidar el pacto -aunque otros lo denominan como la disposición a aceptar (Perevochtikova, 2016).

Así, el proceso político de este modelo de gobernanza ambiental queda subsumido a procesos de financiación. El trazo del diseño y la implementación revela este cariz; su instrumentación progresiva favorece la reificación de los procesos de apropiación de valor mediante la verticalidad de un subsidio montado en un mercado virtual que subsume naturaleza, instituciones locales y modos de vida a principios mercantiles y de especulación financiera (McAfee, 2012), aunque plenamente subvaluados. ${ }^{23}$

${ }^{23}$ En la zona del Ajusco (Ciudad de México), Perevochtchikova (2016, p. 129) tasó el valor del agua por ser captada en 26 veces arriba del monto pagado por Conafor. 
El caso de SinTunich ha sido una ventana para identificar las facetas de la hegemonía de un Estado corporativista y patrimonialista, ocupado en articular mano de obra barata a su favor, pero no en generar ciudadanos partícipes e informados sobre configuraciones complejas. Un armado institucional consolidado en el rentismo, siendo el bosque el recurso y fuente de valor; un artificio ad hoc con fines de cubrir las necesidades políticas y de configuración del poder de la clase política, como se observa en el despliegue de recursos en años de elección federal.

Así, el Estado mexicano se ha ocupado en reproducir las desventajas político-económicas para las poblaciones rurales bajo nuevos mecanismos de esperanza en el desarrollo. Las dádivas monetarias parecen un equivalente de su éxito político: la monetización hacia abajo para el control de la pobreza, mediante la vigilancia y la coerción por los dineros, construye una legitimidad de poder político fragmentario e inestable, aunque parezca más efectiva por su alcance territorial; un consenso forjado de forma transaccional sujeto a la necesidad (pobreza) de algunos de los participantes; aunque también sujeto a la interpelación directa y al reclamo moral de los colectivos sociales que observan un proceso corrupto de las cuentas públicas de instituciones específicas.

Aquí mostré la forma en que los sujetos de política pública bregan con ésta incorporando su propio cálculo: firman los contratos y los cumplen para satisfacer necesidades explícitas en su contexto de pobreza. Un beneficio contingente, una ayuda efímera cuando la vida cotidiana conduce a eventos inesperados: dos mujeres que conocí en SinTunich tuvieron que salir del poblado hacia ciudades cercanas y a la cabecera municipal para recibir atención médica; ninguna contaba con el efectivo suficiente. Una pidió dinero prestado y la otra empeñó una joya para poder resolver sus problemas de salud. Los cálculos para la gente de SinTunich son mayores en una vida cotidiana de escasez de efectivo, y distinguen que el trabajo de turismo reditúa más que la renta del bosque porque genera liquidez relativamente continua; su especulación sobre el bosque es todavía muy básica pues se centra en una apuesta de trabajo asalariado para la siguiente ronda de TMC, sin identificar la desigualdad que se reproduce. ${ }^{24} \mathrm{El}$ esquema de control de

${ }^{24}$ Lo mismo puede entenderse de los hallazgos de Perevotchikova (2016) en el Ajusco.

Estudios Demográficos y Urbanos, vol. 36, núm. 2 (107), mayo-agosto, 2021, pp. 493-532 
la pobreza mediante TMC sirve para paliar algunas necesidades y no para disminuir la desigualdad como pretenciosamente supone el Banco Mundial (Ivaschenko et al., 2018).

Finalmente, en la política ambiental analizada subyace una paradoja real en un contexto de gran desigualdad y de expansión neoliberal como el de México: el mercado virtual se edificó como una estrategia política-económica para beneficio del Estado, pero queda la duda, ¿un mercado abierto abriría riesgos inherentes de privatización del producto principal: el agua? Ante este riesgo, ¿es posible pensar en mercados solidarios viables bajo esquemas de rendición de cuentas?

\title{
Anexo
}

\section{Siglas y acrónimos}

\author{
ANP Áreas Naturales Protegidas \\ APFF Áreas de Protección de Flora y Fauna \\ BM Banco Mundial \\ Cabsa Captura de Carbono, Biodiversidad y Sistemas Agroforestales \\ CACUSTF Compensación Ambiental por Cambio de Uso de Suelo en Terrenos \\ Forestales \\ CDI Comisión de Desarrollo para los Pueblos Indígenas \\ Conabio Comisión Nacional para el Conocimiento y Uso de la Biodiversidad \\ Conafor Comisión Nacional Forestal \\ Conanp Comisión Nacional de Áreas Naturales Protegidas \\ FFM Fondo Forestal Mexicano \\ FPB Fondo Patrimonial de la Biodiversidad \\ GEF Global Environmental Facility \\ ICA Ingenieros Civiles Asociados \\ INEGI Instituto Nacional de Estadística y Geografía \\ LDFS Ley de Desarrollo Forestal Sustentable \\ ONG Organización No Gubernamental \\ OTC Ordenamiento Territorial Comunitario \\ PET Programa de Empleo Temporal \\ Procodes Programa de Conservación para el Desarrollo Sostenible
}


Proders Programa de Desarrollo Rural Sustentable

PSA Pago por Servicios Ambientales

PSAH Pago por Servicios Ambientales Hidrológicos

Semarnat Secretaría del Medio Ambiente y Recursos Naturales

Sinap Sistema Nacional de Áreas Protegidas

TMC Transferencia monetaria condicionada

UAIM Unidad Agrícola Industrial de la Mujer

UMA Unidades de Manejo Ambiental

\section{Bibliografía}

Alix-Garcia, J., Janvry, A., Sadoulet, E., Torres, J., Braña, J. y Zorrilla, M. (2005). An assessment of Mexico's payments for environmental services program. United Nations Food and Agriculture Organization (FAO), Comparative Studies Service Agricultural and Development Economics Division. https://are.berkeley. edu/ esadoulet/papers/FAOPES-aug05.pdf

Banco Mundial (2018). The state of social safety nets. Overview. Washington, D.C: World Bank. https:/openknowledge.world bank.org/bitstream/handle/10986/29115/211254.pdf?sequence $=4$

Brenner, L. y Rosales, R. (2015). Introducción. Procesos de construcción de gobernanza. En R. Rosales Ortega y L. Brenner (coords.), Geografía de la gobernanza. Dinámicas multiescalares de los procesos económico-ambientales (pp. 7-19). Ciudad de México: UAM-Iztapalapa / Siglo XXI.

Bulkeley, H. (2005). Reconfiguring environmental governance: Towards a politics of scales and networks. Political Geography, 24(8), 875-902. Recuperado de https://www.sciencedirect.com/ science/article/pii/S0962629805000880

Calderón, F. (2009). Discurso público del expresidente de la República, Felipe Calderón, en la VII Expo Forestal. https://www. youtube.com/watch? $\mathrm{v}=$ wchAQEo9fEI

Conabio (Comisión Nacional para el Conocimiento y Uso de la Biodiversidad). (2000). Estrategia Nacional sobre Biodiversidad de 
México. Ciudad de México: Comisión Nacional para el Conocimiento y Uso de la Biodiversidad.

Conafor (Comisión Nacional Forestal). (2009). Servicios Ambientales del Bosque. Gerencia de Servicios Ambientales del Bosque. Documento presentado en la VII Expo Forestal. Ciudad de México: Centro Banamex.

Corrigan, P. y Sayer, D. (1985). The great arch: English state formation as a cultural revolution. Oxford: Blackwell.

Fairhead, J., Leach, M. y Scoones, I. (2012). Green grabbing: A new appropriation of nature? Journal of Peasant Studies, 39(2), 237261. Recuperado de https://www.tandfonline.com/doi/full/10.10 80/03066150.2012.671770

Flores, A., Aguilar, R., Reyes, H. y Guzmán, M. (2018). Gobernanza ambiental y pagos por servicios ambientales en América Latina. Sociedad y Ambiente, 16, 7-31. Recuperado de http://revistas. ecosur.mx/sociedadyambiente/index.php/sya/article/view/1811

Gago, V. y Mezzadra, S. (2017). A critique of the extractive operations of capital: Toward an expanded concept of extractivism. Rethinking Marxism, 29(4), 574-591. Recuperado de https://www. tandfonline.com/doi/full/10.1080/08935696.2017.1417087? scroll=top\&needAccess $=$ true

García- Frapolli, E. (2012). Exclusión en áreas protegidas: una aproximación desde los programas de manejo. En L. Durand, F. Figueroa y M. Guzmán (eds.), La naturaleza en contexto. Hacia una ecología política mexicana (pp. 221-236). Morelos, México: UNAM / Colsan.

GEF y BM (Global Environmental Facility y Banco Mundial). (s.f.). Environmental Services Project. [Project ID (GEF/BM) P089171/ P087038]. www.gef.com y www.projects.worldbank. org (consulta: septiembre de 2017).

INEGI (Instituto Nacional de Estadística y Geografía). (2010). XIII Censo de Población y Vivienda. Aguascalientes, México: INEGI. Jessop, B. (2008). State power: A strategic-relational approach. Cambridge: Polity Press.

Jessop, B. y Sum, N. (2006). Beyond the regulation approach: Putting capitalist economies in their place. Londres: Edward Elgar. 
Joseph, G. y Nugent, D. (1994). Everyday forms of state formation: Revolution and the negotiation of rule in modern Mexico. Durham, NC: Duke University Press.

Lapavitsas, C. (2013). Profiting without producing: How finance exploits us all. Londres: Verso.

Lemos, M. C. y Agrawal, A. (2006). Environmental governance. Annual Review of Environmental Resources, 31, 297-325. Recuperado de https://www.annualreviews.org/doi/full/10.1146/ annurev.energy.31.042605.135621

Lezama, J. (2010). Sociedad, medio ambiente y política ambiental, 1970-2000. En J. L. Lezama y B. Graizbord (coords.), Los grandes problemas de México. Vol. IV, Medio Ambiente (pp. 23-60). Ciudad de México: El Colegio de México, A.C.

Lipietz, A. (1986). Behind the crisis: The exhaustion of a regime of accumulation. A regulation school perspective on some French empirical works. Review of Radical Political Economics, 18(1/2), 13-32. Recuperado de https://journals.sagepub.com/doi/ pdf/10.1177/048661348601800102

López, Á. (2015). Turismo y desarrollo sustentable en áreas protegidas o sobre los "nuevos" contrasentidos para la producción y el marasmo en el ámbito rural. Desacatos. Revista de Ciencias Sociales, 47, 36-53. Recuperado de http://desacatos.ciesas.edu.mx/ index.php/Desacatos/article/view/1420/1215

Madrid, L. (2011). Los pagos por servicios ambientales hidrológicos: más allá de la conservación pasiva de los bosques. Investigación Ambiental, 3(2), 52-58. https://agua.org.mx/wp-content/ uploads/2012/04/los_pagos_por_servicios_ambientales_hidrolo gicos.pdf

McAfee, K. (2012). Nature in the market-world. Ecosystem services and inequality. Development, 55(1), 25-33. Recuperado de https://www.academia.edu/1625809/Nature_in_the_Market_ World_Ecosystem_Services_and_Inequality

McAfee, K. y Shapiro, E. (2010). Payments for ecosystem services in Mexico: Nature, neoliberalism, social movements, and the state. Annals of the Association of American Geographers, 100(3), 579-599. Recuperado de https://www.tandfonline.com/ doi/abs/10.1080/00045601003794833 
Merino, L. (2012). Las condiciones de las comunidades forestales mexicanas y la política pública. Recuento de desencuentros. En L. Durand, F. Figueroa y M. Guzmán (eds.), La naturaleza en contexto. Hacia una ecología política mexicana (pp. 33-64). Cuernavaca, Mor., México: UNAM / Colsan.

Merino, L., González, A., Anta, S., Graf, S., Madrid, S., Lara, Y., Ruiz, F., Chapela, F. y Navia, J. (2005). El programa de pago de servicios ambientales hidrológicos: revisión crítica y propuestas de modificación. Ciudad de México: Consejo Civil Mexicano para la Silvicultura Sostenible.

Mezzadra, S. y Neilson, B. (2019). The politics of operations: Excavating contemporary capitalism. Durham, NC: Duke University Press.

Muñoz-Piña, C., Guevara, A., Torres, J. y Braña, J. (2008). Paying for the hydrological services of Mexico's forests: Analysis, negotiations and results. Ecological Economics, 65(4), 725-736. https:/www.sciencedirect.com/science/article/pii/S09218009 07004247

Paz, F. (2012). Conflictos socioambientales, cultura política y gobernanza: la cooperación bajo sospecha en el distrito minero de Molango en el estado de Hidalgo. En L. Durand, F. Figueroa y M. Guzmán (eds.), La naturaleza en contexto. Hacia una ecología política mexicana (pp. 65-94). Cuernavaca, Mor., México: UNAM / Colsan.

Perevochtchikova, M. (2014a). Introducción. En M. Perevochtchikova (coord.), Pago por servicios ambientales en México: un acercamiento para su estudio (pp. 9-14). Ciudad de México: El Colegio de México, A.C.

Perevochtchikova, M. (2014b). Programa de pago por servicios ambientales en México: hacia nuevos esquemas de evaluación. En S. Giorguli Saucedo y V. Ugalde (coords.), Gobierno, territorio y población: las políticas públicas en la mira (pp. 581-609). Ciudad de México: El Colegio de México, A.C.

Perevochtchikova, M. (2016). Estudio de los efectos del Programa de Pago por Servicios Ambientales: experiencia en Ajusco, México. Ciudad de México: El Colegio de México, A.C. 
Scott, J. (2013). Seeing like a state: How certain schemes to improve the human condition have failed. New Haven: Yale University Press.

Semarnat y Conafor (Secretaría de Medio Ambiente y Recursos Naturales y Comisión Nacional Forestal). (2013). Manual operativo del Fondo Patrimonial de Biodiversidad. Ciudad de México.

Smith, G. (2006). When "the logic of capital is the real which lurks in the background". Programme and practice in European regional economies. Current Anthropology, 47(4), 621-639. https:// www.jstor.org/stable/10.1086/504164?seq=1

Trench, T., Larson, A., Libert, A. y Ravikumar, A. (2018). Analyzing multilevel governance in Mexico: Lessons for REDD+ from a study of land-use change and benefit sharing in Chiapas and Yucatán. (Documento de trabajo, 236). Bogor, Indonesia: CIFOR. http://www.cifor.org/publications/pdf_files/WPapers/WP236 Trench.pdf

\section{Acerca de la autora}

Ángeles A. López Santillán es doctora y maestra en Antropología Social por El Colegio de Michoacán, licenciada en Antropología Social por la Escuela Nacional de Antropología e Historia, y egresada y asociada del programa LEAD-Colmex. Desde 2017 es profesora-investigadora del Centro de Investigaciones y Estudios Superiores en Antropología Social (CIESAS), sede Peninsular. Pertenece al Sistema Nacional de Investigadores, nivel I. Sus líneas de investigación son: ecología política, medioambiente y desarrollo, antropología económica y cambio social. Ha colaborado en investigaciones interdisciplinarias, así como en consultorías sobre medio ambiente y recursos colectivos.

Entre sus publicaciones se encuentran:

López Santillán, A. A. (2017). Development, power and exclusionary politics: Tracing articulations of scale in tourism production in Mexico. American Anthropologist, 119, 725-730. https://doi. org/10.1111/aman. 12955 
López Santillán, A. A. (2015). Turismo y desarrollo sustentable en áreas protegidas o sobre los "nuevos" contrasentidos para la producción y el marasmo en el ámbito rural. Desacatos, 47, 36-53. https://doi.org/10.29340/47.1420

Recepción: 11 de octubre de 2018.

Aceptación: 29 de julio de 2019. 